\title{
MECÁNICA TERRESTRE: HUMANISMO Y MODERNIDAD EN LA PRIMERA POESÍA DE CARMEN CONDE (1929-1939) ${ }^{1}$
}

LuIs BAGUÉ Quílez

Universidad Alicante

\section{Yo SOY TU PANORAMA}

La voluntad creadora de Carmen Conde (1907-1996) refleja las principales aventuras estéticas de su tiempo. En los diez años transcurridos desde la publicación de su primer libro hasta el final de la Guerra Civil, la autora recorre las sendas de la poesía moderna, asume su sistema metafórico e interioriza su codificación expresiva. La impronta del simbolismo, las arriesgadas piruetas vanguardistas o la vertiente rehumanizadora del 27 se irán sedimentando como sustrato cultural dentro de su particular universo artístico. Ya en sus escritos iniciales, Carmen Conde ensaya una nueva manera de contemplar la realidad, un simultaneísmo perceptivo que se proyecta sobre el mundo contemporáneo y que sólo se sujeta a los

1 Recibido: 14/XII/2010 Aceptado: 3/II/2011 
límites de la mirada. Sus colaboraciones en Verso y Prosa, Ley (Entregas de capricho) y Colores (1927-1928) responden a los modelos vigentes en el momento, al tiempo que anuncian otros derroteros personales. ${ }^{2}$ La mezcla de retóricas, temas y estilos se advierte igualmente en Brocal (1929), una opera prima que contiene en esencia toda su cosmovisión literaria.

Los poemas en prosa de Brocal se inscriben en un territorio situado a medio camino entre la sugerencia plástica y el destello lírico. El libro se ordena alrededor del sentimiento del paisaje, cuya descripción incorpora rasgos propios del collage. La naturaleza emotiva aparece evocada e invocada mediante un lenguaje que oscila entre la metáfora múltiple y la insinuación pictórica. Carmen Conde demuestra el dominio de un registro impresionista atento al matiz, a los cambios de luz y a la diversidad cromática, pues un mismo contexto permite plasmaciones dispares «al variar su posibilidad óptica». ${ }^{3}$ La superposición de metáforas cristaliza en un espacio sensorial y táctil, como se observa en la siguiente imagen: «Se abrió el paisaje, a todo viento, en la retina». ${ }^{4}$ Brocal diseña una cartografía habitada por la danza de las veletas, la pulsación de los astros, el tañido de las campanas, las torres vigilantes, las aspas de los molinos o los miradores tendidos a la vastedad del horizonte. La naturaleza se convierte en el observatorio desde el que la autora vislumbra el espectáculo de lo visible. De este modo, Carmen Conde construye un discurso en el que convergen la sensibilidad literaria de Juan Ramón Jiménez, el estímulo solar de Gabriel Miró y el verbalismo expansivo de Ramón Gómez de la Serna.

Esta perspectiva determina la densidad simbólica del libro, donde coinciden el deseo de fusión con el paisaje y el anhelo contemplativo. Carmen Conde reivindica un panteísmo basado en la relación cordial entre las cosas. ${ }^{5}$ La despoblada soledad

\footnotetext{
2 Sobre la formación literaria de la autora, pueden consultarse los trabajos de José María Rubio Paredes, La obra juvenil de Carmen Conde, Madrid, Torremozas, 1990; José Luis Ferris, Carmen Conde. Vida, pasión y verso de una escritora olvidada, Madrid, Temas de Hoy, 2007 (especialmente, los capítulos III y Iv), y Manuel J. Ramos Ortega, «El comienzo de una biografía poética: Carmen Conde en las revistas literarias de su primera época (1927-1936)», en Francisco Javier Díez de Revenga y Mariano de Paco (eds.), En un pozo de lumbre. Estudios sobre Carmen Conde, Murcia, Fundación Cajamurcia, 2008, pp. 335-358.

3 Ma Victoria Martín González, «Introducción» a Carmen Conde, Brocal. Edición Centenario 1907-2007, Cartagena, Áglaya, 2007, p. 66.

4 Carmen Conde, Obra poética (1929-1966), Madrid, Biblioteca Nueva, 1979 (2a), p. 37. Cito siempre por esta edición. Para evitar el exceso de notas, indicaré junto a la cita el número de la página correspondiente.
}

5 A este propósito, José María Balcells afirma: «Al mismo tiempo que las cosas se perciben como bellas, también se muestran intrínsecamente en relación entre sí, animadas y armónicas». José María Balcells, «Carmen Conde y el poema en prosa», en Francisco Javier Díez de Revenga y Mariano de Paco (eds.), En un pozo de lumbre, cit., p. 41. 
de «Orilla» y el viaje esférico de «Círculo máximo» obedecen a una mirada que multiplica su objeto y lo descompone en átomos de sentido:

Mi luz recorre todo tu paisaje interior.

Me veo en todo tú hecha mil yos chiquititas; yo, sólo perfil. Yo, sólo frente. Yo, sólo hombros (p. 41).

El lector asiste al nacimiento de un yo «brotando del paisaje, de una realidad metaforizada en vuelo de fantasía y literatura». ${ }^{6}$ Paralelamente, se aprecia una solidaridad afectiva con la naturaleza, en un intento de corporeizar y de reunir sus elementos disgregados: «Formada estoy por molinos, balsas, torres, palomas, rosas...» (p. 40). También hay en Brocal una tendencia a cosificar a las personas y a humanizar lo inanimado, de acuerdo con la dislocación material de las vanguardias. Por una parte, Carmen Conde reproduce estampas cotidianas, caracterizadas por la alusión metonímica a sus personajes. Así sucede cuando describe a las muchachas campesinas - «La campana del cántaro, a la cabeza. Los brazos, sujetando el cielo» (p. 31) - o cuando esboza un autorretrato fragmentario: "Yo, tan delgada como un horizonte, voy por este camino. Cantando. ¡Al viento mis cabellos ondulados, mis cabellos de mapa!» (p. 33). Por otra parte, los objetos adquieren rasgos animales o humanos, gracias a un estilo que participa de la fugacidad imaginística de la greguería y de la percepción deliberadamente ingenua de los ismos: «Las terrazas tienen agilidad de palomas» (p. 29), «[L]os tejados sonríen con los labios rizados de sus tejas» (p. 29), «Las campanas se besan antes del sueño» (p. 32), «El lucero, al final de la tormenta, ha salido muy bien peinado» (p. 35).

Pero Brocal es, sobre todo, un poemario amoroso, un relato sentimental que sugiere una comunión con las fuerzas primordiales. Se trata de un amor casi adolescente, a través de cuyo prisma la autora descubre la realidad circundante:

Brocal es un libro puro y enamorado. Mi juventud extrema y mi amor por el joven poeta, cartagenero como yo, Antonio Oliver Belmás, gestaron su contenido, que aún siento vivo en mi corazón. ${ }^{7}$

Carmen Conde dialoga con el entorno y con su amado, que llegan a fundirse en un único interlocutor. Esa metamorfosis tiene consecuencias en la conversación lírica, ya que el lenguaje del amor se pronuncia con palabras elementales: «¡Yo seré de viento, de llama, de agua! / ¿Qué primavera, qué incendio, qué río me ceñirán mejor que tú?» (p. 31), «El agua que correrá en tus ríos, seré yo. / El alba que abrirá

\footnotetext{
6 Emilio Miró, «La poesía de Carmen Conde», en Carmen Conde, Obra poética (1929-1966), cit., p. 10.

7 Cf. José Luis Ferris, Carmen Conde. Vida, pasión y verso de una escritora olvidada, cit., p. 290.
} 
las claraboyas de tu día, seré yo» (p. 34), «Fluye mi camino al tuyo, como un arroyo a un pino» (p. 35), « ¿Echa al aire mis campanas y mis palmas! Yo soy tu panorama» (p. 38). El énfasis exclamativo deriva a veces en una sentenciosidad rayana en el aforismo: «¡Gira, molino! / Yo soy tu cielo» (p. 36), «No, ¡no era el viento! / Era yo» (p. 36), «¡Yo estaba en los álamos, como el viento de la primavera!» (p. 37), «¡Estaba mi corazón en la lluvia, como una palma roja!» (p. 38).

El carácter dramático se intensifica en «4», un poema en siete actos protagonizado por cuatro hombres vestidos de negro. A pesar de su atmósfera de misterio, el texto abunda en símbolos relacionados con la experiencia de la escritora y con su geografía emotiva. La torre de la catedral de Murcia - escenario del primer beso entre Carmen Conde y Antonio Oliver - o el río Segura se transforman en cómplices de una intimidad compartida. Las pinceladas oníricas y la desconexión entre las secuencias evitan la excesiva emanación confesional y subrayan el tono teatral del conjunto. De hecho, la recreación escénica se cierra con un irónico saludo al espectador: «Los cuatro hombres, altos y enlutados, izaron sus cuatro sombreros planos» (p. 44).

En definitiva, Brocal asimila ciertos aspectos de la modernidad, como el trasfondo lúdico, la metaforización vanguardista y la capacidad asociativa. Sin embargo, su mirada no siempre coincide con la atomización descriptiva que exponen los títulos iniciales de Gerardo Diego - Imagen (1922), Manual de espumas (1924) - , Jorge Guillén - el primer Cántico (1928) - , y, más tarde, Miguel Hernández - Perito en lunas (1933) - . A este respecto, resulta reveladora la opinión de Guillén sobre los modelos que coexisten en los orígenes del 27. El autor distingue entre una poesía escrita bajo la advocación sensorial de Gabriel Miró - él mismo había incluido una cita de Miró en su composición «Jardín en medio» - y otra tendencia centrada en el culto a los sentidos. Ambas prácticas desembocan en dos formulaciones visuales diferentes. En el primer caso, la observación no es ajena al mundo anímico: «La contemplación de Miró se adueña de algo más que una multitud de objetos. A todos los reúne una atmósfera física, espiritual». ${ }^{8}$ Para la segunda corriente, en cambio, la imagen objetiva desempeña el papel principal: «Este cultivo de la imagen es el más común entre los muy diversos caracteres que juntan y separan a los poetas de aquellos años [los 20], y no sólo a los españoles. Imagen se denomina una obra temprana de Gerardo Diego. El cultivo se convierte en un culto supersticioso». ${ }^{9}$ Los primeros textos de Carmen Conde están más cerca de la naturaleza espiritualizada

\footnotetext{
8 Jorge Guillén, Lenguaje y poesía, Madrid, Alianza, 1969, p. 163.

9 Ibid., p. 188.
} 
de Miró que de la despersonalización del 27, si bien su código expresivo se sitúa entre estas dos modalidades.

\section{LA MÁQUINA DE ESCRIBIR ESTÁ CANSADA}

El libro del paisaje se abre otra vez en Júbilos. Poemas de niños, rosas, animales, máquinas y vientos (1934), con prólogo de Gabriela Mistral y dibujos de Norah Borges. Esta colección de estampas se define por la evocación subjetiva y por la ausencia de artificios verbales. Así lo manifiesta Gabriela Mistral en su introducción:

Vivacidad, dulzura y alacridad a un tiempo hay en estas que no querríamos llamar siluetas, porque, como los dibujos japoneses, son criaturas de veras ( $p$. $50)$.

Carmen Conde se concentra en el ámbito de la infancia: por sus páginas desfilan los compañeros de juegos en Cartagena y Melilla («Niños»y «Niñas moras»), los sueños que habitan en el trasmundo inconsciente («Insomnios»), los animales domésticos ligados a la peripecia vital de la autora («Animales»), las flores desprevenidas ante su caducidad («Rosas») y los aires que arrastran la violencia de las fuerzas naturales o históricas («Vientos»). Júbilos recupera el pulso descriptivo de Brocal y transita por senderos que aportan mayor complejidad: a la habilidad de la poeta como retratista de estados del alma y compiladora de apuntes del natural, cabe añadir aquí su destreza en el género memorialístico y en la invención narrativa. Este peculiar mestizaje surge de la combinación - mezclada y agitada - de verso y prosa, poesía y relato, diálogo y narración, desarrollo silogístico y precisión aforística. Además, la escritura de Júbilos se caracteriza por la polifonía y por la multiplicación de los efectos discursivos. Todo ello configura un tipo de texto donde los signos de la modernidad se reflejan en el espejo de la tradición. ${ }^{10}$ Carmen Conde aspira a dotar de un nuevo significado a la naturaleza viva y al material jubiloso que Guillén veía representado en el universo de los objetos cotidianos: «El balcón, los cristales, / Unos libros, la mesa. / ¿Nada más esto? Sí, / Maravillas concretas».11

Dentro de la galería de Júbilos, destaca la sección titulada «Máquinas», que funciona como un capítulo exento sobre las esperanzas y los espejismos del progreso

\footnotetext{
10 Según Jaime Siles, este procedimiento se inspira en la concepción del poema «como mosaico, en el que todas esas variantes de discurso se articulan en una escritura que las contiene tanto como las neutraliza y sintetiza a la vez». Jaime Siles, «El neoconceptismo metafísico de Carmen Conde», en Francisco Javier Díez de Revenga (ed.), Carmen Conde. Voluntad creadora, Madrid / Cartagena / Murcia, Sociedad Estatal de Conmemoraciones Culturales / Ayuntamiento de Cartagena / Comunidad Autónoma de la Región de Murcia, 2007, p. 73.
}

11 Jorge Guillén, Aire nuestro / Cántico, Madrid, Anaya / Mario Muchnik, 1993, p. 25. 
mecánico. Los tres artefactos que protagonizan el apartado-los aeroplanos, la máquina de escribir y la locomotora - se erigen en emblemas de la actualidad técnica. La autora contempla los objetos como depositarios del espíritu de sus poseedores y los «hace comparecer como personajes fantásticos de sus relatos». ${ }^{12}$ Esta personificación de la tecnología resulta tan adecuada para la mentalidad infantil como para la perspectiva naíf de las vanguardias. No obstante, según advierte Cano Ballesta, la novedad de los temas no puede asociarse con el entusiasmo futurista, sino que responde a un impulso más profundo. En estas viñetas no se aprecia el canto a la velocidad ni la exaltación dinámica de la materia inerte. Al contrario, «[e]l sentido y la percepción humanista impregna estos textos: la máquina está al servicio y bajo el control del ser humano». ${ }^{13}$ Carmen Conde se distancia por igual de las visiones edificantes sobre los adelantos científicos - la «Oda a la invención de la imprenta», de Manuel José Quintana, y la «Oda a la vacuna», de Andrés Bello-, del maquinismo intuitivo del 27 - «Las máquinas» (Cántico), de Jorge Guillén - y de los elaborados paisajes cromáticos de la prosa vanguardista - «Los guantes del paisaje» (La flor de Californía, 1928), de José María Hinojosa - . La transformación de la realidad se adapta a un horizonte de expectativas en el que ciencia y poesía no son dos áreas contrapuestas, sino complementarias.

La pieza más breve del conjunto, «Aeroplanos», propone una relectura del mito de Ícaro. En ella, los aeroplanos compiten con las cometas de los niños en su afán por alcanzar «las alas bruñidas del sol» (p. 93). El poema conecta con el entramado visual de la greguería, aunque sacrifica el primer ingrediente de la fórmula ramoniana (humorismo más metáfora) en aras del relieve plástico y de la emoción estética:

Más cerca de las cometas, casi rozando los gritos de los niños, intentaban la última proeza, y pasaban, parando sus hélices en mortal colapso metálico, por la rosa abierta de la tarde (p. 93).

Por su parte, «La máquina de escribir» es un relato breve en el que las máquinas conversan, discuten, sienten envidia o se lamentan de su condición. Aparece ahora el ambiente de trabajo de una oficina, contemplado desde una premisa insólita: «La máquina de escribir está cansada. Desde las nueve de la mañana hasta las cinco y media de la tarde escribe que te escribe. Claro que ella sola, por su gusto e impulso, no es. Obedece a unos dedos suaves, febriles, de mujer» (p. 93). La composición ofrece

\footnotetext{
12 Francisco Javier Díez de Revenga, «Introducción» a Carmen Conde, Antología poética, Madrid, Biblioteca Nueva, 2006, p. 13.

13 Juan Cano Ballesta, «La voz poética de Carmen Conde: del 'bello juego' al desgarro existencial (19291945)», en Francisco Javier Díez de Revenga y Mariano de Paco (eds.), En un pozo de lumbre, cit., p. 77.
} 
un retrato indirecto de la escribiente, en el que las teclas metálicas se identifican con el sujeto femenino:

Cuando sonaban las nueve de la mañana, entró ella en la oficina. Era una muchacha de mediana estatura, cabellos claros y ondulados, ojos oscuros y sonámbulos. Acarició el teclado antes de empezar su tarea (p. 96). ${ }^{14}$

No es difícil averiguar el escenario que pudo servir de inspiración al texto: la sala de calco de la Sociedad Española de Construcción Naval, donde Carmen Conde empezó a trabajar a principios de 1923. De hecho, en unas «Breves notas autobiográficas» - fechadas el 22 de mayo de 1925-, la escritora ensayaba una prosopopeya de su máquina de escribir, si bien desde la óptica inversa (desde el sujeto al objeto):

\footnotetext{
Me espera mi maquinita, mi flamante Underwood; la máquina, que no deja de ayudarme a confeccionar primores, me exige copias y más copias de unos endemoniados trabajos de revisión...

Y trabajo, trabajo intensamente. Los tipos, alegremente, van alineando en el papel satinado palabras y guarismos que no entiendo... frente a mí el oficinesco reloj de pared, marcha lento, ¡lento como la desesperación....! ${ }^{15}$
}

El tema y el enfoque de «La máquina de escribir» son recurrentes en la literatura de vanguardia. Ejemplo de esta genealogía es «Underwood girls» (Fábula y signo, 1931), de Pedro Salinas, que comparte con Carmen Conde su técnica caleidoscópica y su planteamiento perspectivista. Con todo, la observación de un objeto desde distintos ángulos adquiere en Salinas una dimensión mítica. Su poema se dirige hacia una conclusión donde la reflexión intelectual predomina sobre la experiencia cotidiana: «Tú alócate / bien los dedos, y las / raptas y las lanzas, / a las treinta, eternas ninfas / contra el gran mundo vacío, / blanco en blanco. / Por fin a la hazaña pura, / sin palabras, sin sentido, / ese, zeda, jota, $i \ldots{ }^{\prime 1}{ }^{16}$

${ }_{14}$ Este autorretrato guarda un parecido familiar con la semblanza que Aleixandre le dedicó a Carmen Conde en Los encuentros: «¿Delineante? ¡Lo que sea! Va a su oficina; tiene una mano segura, una frente con bucles, inclinada, y un pecho que le late sobre el compás y el tiralíneas y las grandes planas ciegas de los tableros». Vicente Aleixandre, «En pie, Carmen Conde», en Los encuentros, Barcelona, Guadarrama, $1977\left(2^{\mathrm{a}}\right)$, pp. 170-171.

15 Cf. José Luis Ferris, Carmen Conde. Vida, pasión y verso de una escritora olvidada, cit., p. 148.

16 Pedro Salinas, Poesías completas, Barcelona, Barral, 1971, pp. 203-204. En palabras de Díez de Revenga, «[e]s la personificación de las teclas la que provoca sensaciones de quietud (dormidas, quietas), recreos visuales en colores y formas (redondas, blancas), sugerencias a través de metáforas e imágenes (las nubes capaces de producir una lluvia metafórica de signos que representan la realidad), o alusiones auditivas (el sonido de las teclas crea un vals metálico, moderno, mecánico, nuevo en definitiva...)». Francisco Javier Díez de Revenga, «Selección y comentarios (Pedro Salinas)», en VV.AA., Poetas del 27. La generación y su entorno: Antología comentada, Madrid, Espasa-Calpe, 1998, p. 110. 
Asimismo, la máquina de escribir se erige en personaje de algunos textos en prosa de la época. La animación de lo inanimado permite reemplazar el soporte realista por una concepción transmutada de la realidad, que favorece la irrupción del humor y de la ironía. Prueba de ello es «Medusa artificial» (El boxeador y un ángel, 1929), de Francisco Ayala. El epígrafe inicial del relato, titulado «Mari-Tere, taquimeca», muestra una transferencia afectiva que anticipa el citado fragmento de Carmen Conde:

Tere encerró su typewriter en rizada concha de madera. «Ya, hasta mañana pensó - , su triple fila de botones no salpicará violetas pequeñas; no cantará en su jaula, ni se mecerá de un lado a otro con voluptuosidad de piano. Ya, hasta mañana...». ${ }^{17}$

Por último, «La locomotora» dialoga con la narrativa infantil. En los primeros compases, la autora realiza un estudio del paisaje que intenta expresar la continuidad de sensaciones vislumbradas desde la ventanilla de un tren. Sin embargo, «La locomotora» no se limita a formular «la misma teoría de montañas, riachuelos, lagunas, campos llanos, porque los cristales se sabían de memoria el panorama y lo repetían sin verlo» (p. 96). El cuento también puede leerse como una fábula poética, una alegoría sobre la vejez y sobre la convivencia entre el mundo natural y el mundo mecánico. La anciana locomotora que protagoniza la narración, retirada de la circulación y convertida en pieza de museo, vuelve a caminar por los rieles de una huerta gracias al ingenio de un joven profesor de Mecánica:

¡Qué enorme felicidad la que atravesó la frente de la locomotora! A pesar del profesor viejo, partidario de la estática; por gracia del profesor joven, que reía viendo desperezarse los músculos, las ruedas, las bielas ya templadas.

Aunque bajaran la noche y el olvido y toda la Escuela Industrial permaneciera callada, la locomotora era dichosa. Porque siempre esperaría que las manos de los niños la acariciaran en sus ya no enmohecidas velocidades, aunque fuera para un crucero de parte a parte del huerto (p. 98). ${ }^{18}$

Carmen Conde defiende la armonía entre el progreso y la naturaleza. En «La locomotora» se escuchan ecos de la poesía de Juan Ramón Jiménez - «En tren» (Melancolía, 1910-1911) y «El tren lejano» (Historias, 1909-1912) - y de la prosa de Azorín - «Los ferrocarriles» (Castilla, 1912) - . A su vez, algunos pasajes remiten

${ }_{17}$ Francisco Ayala, Cazador en el alba y otras imaginaciones, Barcelona, Seix Barral, 1971, p. 119.

18 Este corolario entronca con el ensayo «Maquinismo», de Gómez de la Serna, en el que reaparecen las locomotoras que hibernan en los almacenes de las estaciones: «Como elefantiásicos profesores de música, las locomotoras forman esos semicírculos en que se reúnen al carbonear en los depósitos de máquinas que hay en los aledaños de las grandes estaciones [...]. Los viejos maquinistas, ennegrecidos por los viajes, abren los escapes y entrelazan los pitidos como cuando en el inmenso valle se cruzan unos trenes con otros». Ramón Gómez de la Serna, Ismos, Madrid, Guadarrama, 1975, p. 159. 
a «El tren» (Campos de Castilla, 1912), de Antonio Machado, una estampa recorrida por el vértigo de la velocidad: «El tren camina y camina, / y la máquina resuella, / $\mathrm{y}$ tose con tos ferina. / ¡Vamos en una centella!». ${ }^{19}$

En suma, la autora se propone insertar la región de las vanguardias en el mapa de la modernidad lírica, que abarca desde el simbolismo finisecular hasta el arte deshumanizado de entreguerras. El desbordamiento metafórico de Júbilos clausura una etapa de aprendizaje y abre un periodo más personal y ambicioso, indisociable de su conocimiento de la realidad.

\section{SE DESPLOMÓ LA PAZ}

Los siguientes libros de Carmen Conde se enmarcan dentro de unas circunstancias históricas que condicionan la escritura y los temas abordados. De hecho, Sostenido ensueño (1938) y Mientras los hombres mueren (1938-1939) permanecieron inéditos durante varias décadas: el primero no se publicó hasta la aparición de la Obra poética de la autora, mientras que el segundo se imprimió en 1952, en la editorial Cisalpino de Milán. La estrategia adoptada ante el estallido de la Guerra Civil es diferente en ambos casos: si Sostenido ensueño pretende huir del dolor mediante la naturaleza exultante y los claroscuros de la identidad, Mientras los hombres mueren apuesta por una aproximación directa al sufrimiento. En estos títulos, la escritora se enfrenta a la destrucción de las ilusiones colectivas con una voz propia. No obstante, en Mientras los hombres mueren se advierte con mayor nitidez la vocación rehumanizadora.

Carmen Conde ofrece aquí una visión desolada sobre la contienda. El libro recupera el trasfondo simbólico de Júbilos - del que constituye su contrapunto tonal y avanza hacia una estética expresionista, anunciada en ciertas facetas de Sostenido ensueño. De esta manera, Mientras los hombres mueren no es tanto un documento realista como un testimonio lírico. La autora trata de «dar cuerpo emocional, en un lenguaje que no rehúye el alto vuelo imaginativo y aun irracional, a su respuesta angustiada y a veces violenta ante el espectáculo de la tierra manchada por la sangre y la muerte». ${ }^{20} \mathrm{El}$ ideario reformista de la escritora y su compromiso pedagógico, materializados en iniciativas específicas - la fundación de la Universidad Popular de Cartagena y el volumen La escuela renovada (1931), que propugnaba el derecho a la educación para todas las clases sociales - , se desvanecen ante el sombrío panorama

\footnotetext{
19 Antonio Machado, Poesías completas, Madrid, Espasa-Calpe, $1997\left(27^{\mathrm{a}}\right)$, p. 167.

20 Zenaida Gutiérrez-Vega, «La experiencia poética de la guerra en Carmen Conde», Cuadernos para Investigación de la Literatura Hispánica, núm. 8, 1987, p. 149.
} 
del presente. La nota preliminar de Mientras los hombres mueren proporciona su pauta interpretativa:

Mientras los hombres mueren fue escrito en un tiempo de intenso dolor por lo que la guerra destruía y seguirá destruyendo. No unos hombres determinados, sino todos los hombres son llorados aquí con el profundo desconsuelo que siente una mujer ante los inescrutables designios que permiten el horror donde vivía la confiada sonrisa (p. 186).

El vitalismo de sus textos anteriores se transforma en un grito desgarrado, una apelación a la fraternidad y un clamor antibelicista. Con todo, la épica cordial de Carmen Conde se impone a la llamada combativa de otros autores, como Rafael Alberti (De un momento a otro, 1937) o Miguel Hernández (Viento del pueblo, 1937; El hombre acecha, 1939). La actitud de la poeta está tan alejada del canto hímnico como del lamento elegíaco. Si bien sus versos recogen la vivencia de la guerra desde una trinchera concreta (el bando republicano), el eco de su onda expansiva alcanza todas las trincheras del mundo, más allá de cualquier clase de simpatía ideológica. ${ }^{21}$ Carmen Conde postula una poesía del desconsuelo articulada en torno a tres ejes: la solidaridad con el sufrimiento humano, el sentido asignado a la dicotomía naturaleza / civilización y la reivindicación de una mirada femenina, desde cuya perspectiva se contempla el desenlace de la batalla.

En primer lugar, cabe resaltar el deseo de solidarizarse con el dolor de toda índole. Esta voluntad comprensiva explica la presencia de una muerte omnisciente, que reside en las fuerzas esenciales de la naturaleza y que difumina los papeles de víctimas y verdugos. En última instancia, Carmen Conde sólo distingue dos opciones: la inocencia de los vencidos y la responsabilidad de los supervivientes. Los poderes cósmicos se confabulan en un nuevo simbolismo, que exige una resemantización de las metáforas naturales adscritas al agua, al viento y al fuego. ${ }^{22}$ En el agua confluyen la fuente de la vida y el cauce del destino, formalizados en la codificación simbólica del mar manriqueño - «En la más ahondada raíz del mar clavaron mis hermanos sus gritos de terror» (p. 188) - y del diluvio bíblico: «Caerá

${ }^{21}$ Cf. Leopoldo de Luis «Mientras los hombres mueren», Zurgai, diciembre de 1996, pp. 48-50, y Emilio Miró, «La poesía 'civil' de Carmen Conde», en Francisco Javier Díez de Revenga y Mariano de Paco (eds.), En un pozo de lumbre. Estudios sobre Carmen Conde, cit., pp. 233-255.

22 En una anotación de Empezando la vida. Memoria de una infancia en Marruecos (1914-1920), Carmen Conde reconocía «[u]n miedo espantoso a tres de los elementos fundamentales: Fuego, Aire y Agua. La Tierra no me asustaba entonces; era mi infancia tan tierna que aún era yo de la tierra para sentirla ajena; y no la temía. // ¡El Fuego!... Dos incendios en mi casa y uno en la calle cercana, en un almacén de petróleo. ¡El Aire!... Ese viento copudo, bravucón, que empuja salvajemente cuanto ve a su paso; viento del desierto, arenoso y ensordecedor. ¡El Mar!... El mar de allí, bramando día y noche en amenaza de alzarse sobre sí y saltar por las calles y casas para llevarse a sus cuevas las vidas temblorosas de los niños...» (p. 130). 
el Agua siempre, inextinguible, juntando las tierras donde pace hoy anchamente el Duero» (p. 203). El aire agrega, a su condición devastadora, un original valor de mensajero trágico, según se aprecia en el fragmento titulado «La muerte en el aire» (p. 189). Finalmente, el fuego representa la antorcha de la esperanza, que se consume en una combustión profética: «iVed mi llama, acercaos a mi lumbre! Soy un grito que el fuego dejó entre vosotros los que odiáis la Primavera, y arderé hasta incendiaros los ojos" (p. 199). Esta invocación incluye a la autora, que recibe las órdenes de los elementos, se encarna en sus perfiles y se convierte en emisaria de una oscura noticia:

El Mar me dio su orden exacta, incorporándose mis ojos en dos barcas de quillas redondas. Me la dio el Viento, adueñándose de mis cabellos para extenderlos en rubio pañuelo de olor. La recibí de la Tierra, creciéndome, columnas de mis piernas arriba, con un estremecimiento inextinguible y frutal. ¡Todos los que mandan, hasta el Fuego, me han dicho ya lo que quieren de mí! (p. 194).

Junto con la carga significativa que Carmen Conde concede a la naturaleza, aparecen otras imágenes de similar intensidad, pero de origen menos evidente. Se trata de expresiones surgidas de la fusión de sinestesias o de un sistema asociativo de raíz visual. En esta dirección se orientan los fogonazos irracionales que prefiguran la iconografía tentacular y las adherencias verbales del Dámaso Alonso de Hijos de la ira (1944), en ocasiones acentuadas por la composición léxica: «Las verdes caracolas del espanto, y los atronadores murmullos del terror, y el viscoso largo-azul dedo del miedo...» (p. 207). Asimismo, se filtra en los versos una imaginería propia, condensación de un dolor cósmico que yuxtapone nacimiento y muerte: «incendio, también, de tumbas en la noche sin orilla de la inmensa Noche del Duelo de las Esferas!» (p. 195)

En segundo lugar, Mientras los hombres mueren se estructura sobre la oposición entre naturaleza y civilización. Si en Brocal la autora se sentía «reclamada por la Naturaleza invasora», ${ }^{23}$ y en Júbilos intentaba compatibilizar el horizonte natural y el técnico, la convivencia entre atavismo y progreso resulta ahora inviable. La identificación de los avances científicos con la maquinaria bélica se despliega en la sección «A los niños muertos por la guerra», que tematiza la lucha entre el hombre y la tecnología. La valoración negativa de la civilización obedece a un cambio «operado en su misma cosmovisión, que ahora desconfía de la cultura y busca garantías en el refrendo de la naturaleza». ${ }^{24}$ A partir de esta premisa, el libro se organiza en torno a la contraposición entre la vitalidad humana y la deshumanización objetual. Esta

${ }_{23}$ Dámaso Alonso, «Pasión de Carmen Conde», en Poetas españoles contemporáneos, Madrid, Gredos, $1978\left(3^{\mathrm{a}}\right)$, p. 341.

24 Jaime Siles, «El neoconceptismo metafísico de Carmen Conde», cit., p. 73. 
dicotomía se distribuye en dos campos semánticos antagónicos. Por un lado, se encuentran aquellos símbolos que aluden al áspero metal de las armas: las «púas de las ametralladoras» (pp. 207-208), «los cilindros por donde se derrama el odio» (p. 208), «la espoleta helicoidal de la bomba» (p. 208), las «cuchillas de acero» (p. 208), «la ronca metralla enemiga» (p. 209), «una muerte múltiple, enmarañada de cascotes y de trilita» (p. 209), «una mano de hierro» (p. 209), «los obuses de los cañones del odio» (p. 212) o las «cortezas de hierro estallado» (p. 213). Por otro lado, abundan los términos relacionados con una simbología ascensional y germinativa: «las alas que rajan el curvo cielo de las noches cóncavas» (p. 208), «un verde racimo» (p. 209), «flor de azúcares» (p. 209), «niños tiernos del abrazo» (p. 209), «el dolor del trigo» (p. 212) o los «cuerpos de espiga tierna» (p. 213). Este juego dialéctico afecta a otras parejas de oposiciones: pulsión afirmativa frente a esfuerzo destructivo, libertad moral frente a soledad ontológica, heroísmo frente cobardía, así como «los binomios luz / sombra, alba / noche, [que] parecen estar en función de los ya referidos, y sustanciales, de muerte / vida y su consecuente guerra / paz». ${ }^{25}$

En tercer lugar, la mirada femenina otorga una nueva dimensión ética al conjunto. Es necesario mencionar al respecto la importancia de la tierra, pues alrededor de ella gravitan las fuerzas cósmicas. El componente telúrico adquiere matices compasivos, lejos de la voracidad destructora de los demás elementos. Carmen Conde desarrolla la metáfora de una tierra madre que sufre al ver a sus hijos arrancados antes de tiempo y que se niega a perpetuar la violencia cainita. La poeta exhorta a las mujeres, el único poder biológico capaz de detener el círculo de concepción y muerte desencadenado por la guerra. Por tanto, el tema de la maternidad se refleja desde un enfoque subversivo, que introduce una llamada a la insurrección frente a los roles tradicionales: «iNegaos a parir al hombre que mañana matará al hombre hijo de tu hermana, a la mujer que parirá otro hombre para que mate a tu hermano!» (p. 210). En otros casos, la figura de la mujer-madre se convierte en el icono de un ciclo vital ajeno al impulso funerario. ${ }^{26}$ De acuerdo con el panteísmo de la autora, la tierra no es una materia pasiva, susceptible de ser conquistada, sino un espacio activo de creatividad y regeneración. Después de este proceso, el hondo telurismo de Carmen Conde desemboca en la construcción de una mujer nueva, que reclama un sitio en la historia. ${ }^{27}$ Este planteamiento conduce

\footnotetext{
25 Zenaida Gutiérrez-Vega, «La experiencia poética de la guerra en Carmen Conde», cit., p. 153.

${ }^{26}$ La corporeización de la angustia está vinculada a una espiritualidad de trasfondo cristiano: «Pero soy una madre crucificada en todos los niños que saltaron en chispas por ímpetu de la ronca metralla enemiga» (p. 209).

27 Cf. Lynda J. Jentsch, «Fatalmente traspasada: Carmen Conde on war and wholeness», España Contemporánea. Revista de Literatura y Cultura, núm. 1, 1997, pp. 23-36, y María Payeras Grau, «La obra de Carmen Conde entre dos generaciones poéticas», en Francisco Javier Díez de Revenga y Mariano de Paco
} 
a la reinterpretación de algunos mitos y arquetipos, como ocurre con la Eva bíblica de Mujer sin Edén (1947).

El mensaje de Mientras los hombres mueren se sintetiza en el desengañado epítome de «Ha terminado la guerra»: «Se desplomó la paz» (p. 206). No obstante, la proyección hacia el futuro permite abrir un resquicio a la esperanza: « ¡Traednos a los niños, hombres vencedores! Necesitamos su antorcha sobre nuestras frentes» (p. 215). ${ }^{28}$

Carmen Conde elabora una mecánica terrestre que invierte y actualiza la «Mecánica celeste» propugnada por Jorge Guillén. La autora no cifra el porvenir en el entusiasmo fabril y maquinista que deslumbró a sus coetáneos (véase «La fábricaciudad», de Miguel Hernández). Al contrario, su obra se localiza a medio camino entre una poesía arraigada - que concibe la ternura como un modo de rebeldía - y una poesía desarraigada - que relata su expulsión del paraíso y su experiencia en un mundo de fugitivos - . El compromiso singular con la libertad, con la modernidad y con el humanismo ha condenado a Carmen Conde a una imprecisa tierra de nadie, lejos de la iluminada tierra que alumbró en sus versos. Sin embargo, una (re)lectura sin dogmas ni prejuicios debe atender a las posibilidades de una voluntad creativa que la poeta supo plasmar en su epistolario ficticio con la escritora modernista Katherine Mansfield (1888-1923): «Quiero crear, quiero dar forma y sonido a lo que puebla mis venas. Quiero volver mis ojos hacia adentro cuando ya dentro no queden paisajes que decir».

\section{Bibliografía}

AleixAndre, Vicente, «En pie, Carmen Conde», en Los encuentros, Barcelona, Guadarrama, $1977\left(2^{\mathrm{a}}\right)$, pp. 170-173.

Alonso, Dámaso [1969], «Pasión de Carmen Conde», en Poetas españoles contemporáneos, Madrid, Gredos, 1978 (3ª), pp. 339-344.

Ayala, Francisco, Cazador en el alba y otras imaginaciones, Barcelona, Seix Barral, 1971. BALCells, José María, «Carmen Conde y el poema en prosa», en Francisco Javier Díez de Revenga y Mariano de Paco (eds.), En un pozo de lumbre, pp. 33-56.

CAno Ballesta, Juan, «La voz poética de Carmen Conde: del 'bello juego' al desgarro existencial (1929-1945)», en Francisco Javier DíEz DE Revenga y Mariano DE

(eds.), En un pozo de lumbre. Estudios sobre Carmen Conde, cit., pp. 307-333.

28 Las diversas vertientes de esta poesía civil resuenan en algunas voces contemporáneas. Así, el tema de la maternidad culpable aparece en Color carne (2009), de Erika Martínez, mientras que la invocación mesiánica a los niños recorre los cantos de La marcha de 150.000.000 (2009), de Enrique Falcón. 
Luis Bagué Quílez

PACo (eds.), En un pozo de lumbre, pp. 71-85.

Conde, Carmen [1967], Obra poética (1929-1966), Madrid, Biblioteca Nueva, 1979 (2ª).

Conde, Carmen, Antología poética, Madrid, Biblioteca Nueva, 2006.

Conde, Carmen, Brocal. Edición Centenario 1907-2007, Cartagena, Áglaya, 2007.

FERrIs, José Luis, Carmen Conde. Vida, pasión y verso de una escritora olvidada, Madrid, Temas de Hoy, 2007.

Díez de Revenga, Francisco Javier, «Selección y comentarios (Pedro Salinas)», en

VV.AA., Poetas del 27. La generación y su entorno: Antología comentada, Madrid,

Espasa-Calpe, 1998, pp. 99-143.

Díez de Revenga, Francisco Javier, «Introducción» a Carmen Conde, Antología poética, pp. 7-37.

Díez de Revenga, Francisco Javier (ed.), Carmen Conde. Voluntad creadora, Madrid

/ Cartagena / Murcia, Sociedad Estatal de Conmemoraciones Culturales / Ayuntamiento de Cartagena / Comunidad Autónoma de la Región de Murcia, 2007.

Díez de Revenga, Francisco Javier y Mariano de Paco (eds.), En un pozo de lumbre.

Estudios sobre Carmen Conde, Murcia, Fundación Cajamurcia, 2008.

Gómez de la SERnA, Ramón, Ismos, Madrid, Guadarrama, 1975.

Guillén, Jorge, Lenguaje y poesía, Madrid, Alianza, 1969.

Guillén, Jorge, Aire nuestro / Cántico, Madrid, Anaya / Mario Muchnik, 1993.

Gutiérrez-VeGA, Zenaida, «La experiencia poética de la guerra en Carmen Conde»,

Cuadernos para Investigación de la Literatura Hispánica, núm. 8, 1987, pp. 149155.

Jentsch, Lynda J., «Fatalmente traspasada: Carmen Conde on war and wholeness»,

España Contemporánea. Revista de Literatura y Cultura, núm. 1, 1997, pp. 23-36.

LuIs, Leopoldo de, «Mientras los hombres mueren», Zurgai, diciembre de 1996, pp. 48-50.

Machado, Antonio [1975], Poesías completas, Madrid, Espasa-Calpe, 1997 (27ª).

Martín GonzÁlez, Ma Victoria, «Introducción» a Carmen Conde, Brocal. Edición Centenario 1907-2007, pp. 5-77.

Miró, Emilio, «La poesía de Carmen Conde», en Carmen Conde, Obra poética (19291966), pp. 9-23.

Miró, Emilio, «La poesía 'civil' de Carmen Conde», en Francisco Javier Díez DE Revenga y Mariano de Paco (eds.), En un pozo de lumbre, pp. 233-255.

Payeras Grau, María, «La obra de Carmen Conde entre dos generaciones poéticas», en Francisco Javier Díez de Revenga y Mariano De PAco (eds.), En un pozo de lumbre, pp. 307-333.

Ramos Ortega, Manuel J., «El comienzo de una biografía poética: Carmen Conde en las revistas literarias de su primera época (1927-1936)», en Francisco Javier 
Mecánica terrestre: humanismo y modernidad en la primera poesía de Carmen Conde (1929-1939)

Díez de Revenga y Mariano de Paco (eds.), En un pozo de lumbre, pp. 335-358. Rubio Paredes, José María, La obra juvenil de Carmen Conde, Madrid, Torremozas, 1990.

Salinas, Pedro, Poesías completas, Barcelona, Barral, 1971.

SILES, Jaime, «El neoconceptismo metafísico de Carmen Conde», en Francisco Javier Díez de Revenga (ed.), Carmen Conde. Voluntad creadora, pp. 69-81. 